\title{
Osteoarthritis- a systematic review of long-term safety implications for osteoarthritis of the knee
}

\author{
Jonathon Charlesworth $^{1^{*}}$ (D), Jane Fitzpatrick ${ }^{1,3,4}$, Nirmala Kanthi Panagodage Perera ${ }^{1,2}$ and John Orchard ${ }^{1,5}$
}

\begin{abstract}
Background: There is no cure for knee osteoarthritis (KOA) and typically patients live approximately 30-years with the disease. Most common medical treatments result in short-term palliation of symptoms with little consideration of long-term risk. This systematic review aims to appraise the current evidence for the long-term ( $\geq 12$ months) safety of common treatments for knee osteoarthritis (KOA).
\end{abstract}

Methods: Cochrane Database of Systematic Reviews, Medline and PubMed were systematically searched from 1990 to July 2017, inclusive. Inclusion criteria were 1) peer-reviewed publications investigating treatments for KOA referred to in the Australian Clinical Care Standard and/or Therapeutic Guidelines: Rheumatology 2) specifically addressing safety of the treatments 3) with $\geq 12$ months of follow-up and 4) Downs and Black quality score $\geq 13$.

Results: Thirty-four studies fulfilled the inclusion criteria. Lifestyle modifications (moderate exercise and weight loss), paracetamol, glucosamine, Intraarticular Hyaluronic Acid (IAHA) and platelet-rich-plasma (PRP) injections have a low risk of harm and beneficial $\geq 12$ month outcomes. Although Nonsteroidal Anti-inflammatory Drugs (NSAIDs) provide pain relief, they are associated with increased risk of medical complications. Cortisone injections are associated with radiological cartilage degeneration at $>12$ months. Arthroscopy for degenerative meniscal tears in KOA leads to a 3-fold increase in total knee arthroplasty (TKA). TKA improves primary outcomes of KOA but has a low rate of significant medical complications.

Conclusions: Given the safety and effectiveness of lifestyle interventions such as weight loss and exercise, these should be advocated in all patients due to the low risk of harm. The use of NSAIDs should be minimized to avoid gastrointestinal complications. Treatment with opioids has a lack of evidence for use and a high risk of long-term harm. The use of IAHA and PRP may provide additional symptomatic benefit without the risk of harm. TKA is associated with significant medical complications but is justified by the efficacy of joint replacement in late-stage disease.

Trial registration: PROSPERO International prospective register for systematic reviews; registration number CRD42017072809.

Keywords: Osteoarthritis, Knee, Exercise, Injections, Surgery

\section{Background}

Osteoarthritis (OA) is a chronic degenerative joint disease of dynamic pathology with multifactorial aetiology. It involves progressive softening and loss of articular cartilage, subchondral bone sclerosis, cyst formation and the development of osteophytes. OA of the knee accounts for more dependence in walking, stair climbing and other

\footnotetext{
* Correspondence: jonathoncharlesworth@hotmail.com

${ }^{1}$ Australasian College of Sport and Exercise Physicians, 257 Collins Street, Melbourne, VIC 3000, Australia

Full list of author information is available at the end of the article
}

lower-extremity tasks that any other disease [1]. To illustrate the impact of knee OA (KOA) on a typical population in a Western country, we've chosen example references from Australia, familiar to our author group. International comparison studies show that Australia's rate of $\mathrm{KOA}$ is similar to other Western nations and affects 2.1 million Australians (9\% of the population) [2]. Large numbers of arthroplasties are performed due to $\mathrm{KOA}$; in 2015, 54,277 total knee arthroplasty (TKA) surgeries were performed in Australia due to KOA [3].

(c) The Author(s). 2019 Open Access This article is distributed under the terms of the Creative Commons Attribution 4.0 International License (http://creativecommons.org/licenses/by/4.0/), which permits unrestricted use, distribution, and reproduction in any medium, provided you give appropriate credit to the original author(s) and the source, provide a link to the Creative Commons license, and indicate if changes were made. The Creative Commons Public Domain Dedication waiver (http://creativecommons.org/publicdomain/zero/1.0/) applies to the data made available in this article, unless otherwise stated. 
The median age of KOA diagnosis is 55-years and typically people live about 30-years with the disease [4]. As there is no curative treatment for OA currently; treatments are aimed at reducing pain and improving function. Systematic reviews (SR) are a useful method to synthesise the efficacy of treatments for KOA, however most of these reviews have not considered the long-term risks associated with treatments. This was because most studies follow patients for a short period of time (e.g. 3-6 months). This results in a significant evidence gap in the literature because it is likely that short-term improvements such as pain relief are overrepresented whilst potential long-term risks might be underrepresented in these studies. Given that a patient with KOA lives with their condition for an average of 30-years, an evidence-based understanding of the safety of treatments is important to ensure patient safety. This review aims to appraise the current evidence for long-term ( $\geq 12$ months) safety of common treatments for KOA.

\section{Methods}

Three databases (Cochrane Database of Systematic Reviews, Medline and PubMed) were systematically searched from 1990 to July 2017 inclusive, following the Preferred Reporting Items for Systematic Reviews and Meta-analysis (PRISMA) guidelines [5]. A priori study protocol was registered on the PROSPERO International prospective register for systematic reviews (http://www.crd.york.ac.uk/PROSPERO/display_record.php?ID=CRD42017072809); registration number CRD42017072809. The PICO (population, intervention, comparator/control and outcome) concept [6] was used to develop search strategy (Appendix 1) and the inclusion/exclusion criteria (Appendix 2). Studies were considered if they were: 1 ) peer reviewed publications investigating treatments for KOA listed in the Australian Clinical Care Standard [7] and/or Therapeutic Guidelines: Rheumatology [8], 2) specifically addressed safety of the treatments; 3) with $\geq 12$ months of follow-up and 4) Downs and Black [9] quality score $>13$ (Appendix 2). A study was excluded from the review if it failed a single criterion.

The 'long-term effect' for KOA treatments was defined as any effect which persisted $\geq 12$ months post-treatment. For treatments that were used on a single occasion and discontinued (e.g. surgery, injections), the follow-up period after treatment was determined to be at least 12 months. With respect to ongoing treatments (e.g. analgesia), an independent measure of disease-modification was required. This was to avoid the issue of repeated short-term effects potentially masking long-term effects of ongoing treatment. Minor side effects and adverse events (e.g. allergic rash, post-procedure soreness) were not included in this review as they are typically short-term issues. However, adverse events such as drug addiction and cardiovascular issues were included as these could persist beyond 12 months. Long-term effect of a treatment could be either:
(1) positive OR negative effect of index treatment vs comparison treatment in any trial persisting at $\geq 12$ months; or

(2) positive OR negative effect of index treatment vs comparison treatment in any trial showing significant change in any objective disease indicator (e.g. cartilage thickness on magnetic resonance imaging (MRI) or X-ray) at $\geq 12$ months; or

(3) effect of index treatment showing significantly increased OR reduced risk of progression to TKA; or

(4) significant increase in side-effect or harm related to treatment with a potential for ongoing harm from this condition to persist beyond 12 months

\section{Results}

Study selection

Of the 880 records identified in the initial keyword search, 34 studies fulfilled the inclusion criteria, had a Downs and Black [9] quality score $\geq 13$ (Appendix 2) and are included in the synthesis (Fig. 1). A summary of included studies including study population characteristics, medium-long term treatment impact on the disease and non-disease side effects that have the potential to last 12 months are presented in Table 1.

\section{Methodological quality}

Results of the Downs and Black [9] methodological quality assessment was presented in Additional file 1: Table S1. No study received score $\leq 13$. Twenty-two studies $[11-21,25-29,32,33,37,39,42]$ reached the maximum quality score of 22 out of 26 and thus have a low risk of bias. The mean score was 21 .

\section{Overview of the treatment options Lifestyle modification}

Exercise Four studies [10-13], including 839 patients investigated exercise as treatment for KOA. Clinically significant improvements in Western Ontario and McMaster Universities Osteoarthritis Index (WOMAC), Visual Analogue Scale (VAS) and Knee injury and Osteoarthritis Outcome Score (KOOS) were found at 1-year with no adverse events (Table 1 ).

Weight reduction Two studies [12, 14], including 956 patients investigated the role of weight reduction as treatment for KOA and no adverse outcomes were reported. Eighty-two patients who were on a dietary intervention aimed for an average of $5 \%$ weight loss over 18 months and subsequently reported an $18 \%$ improvement in WOMAC scores [12]. In addition, participants who lost more than $5 \%$ of their body weight over 48 months showed significantly lower cartilage degeneration on MRI compared to those in the stable weight group [14] (Table 1). 


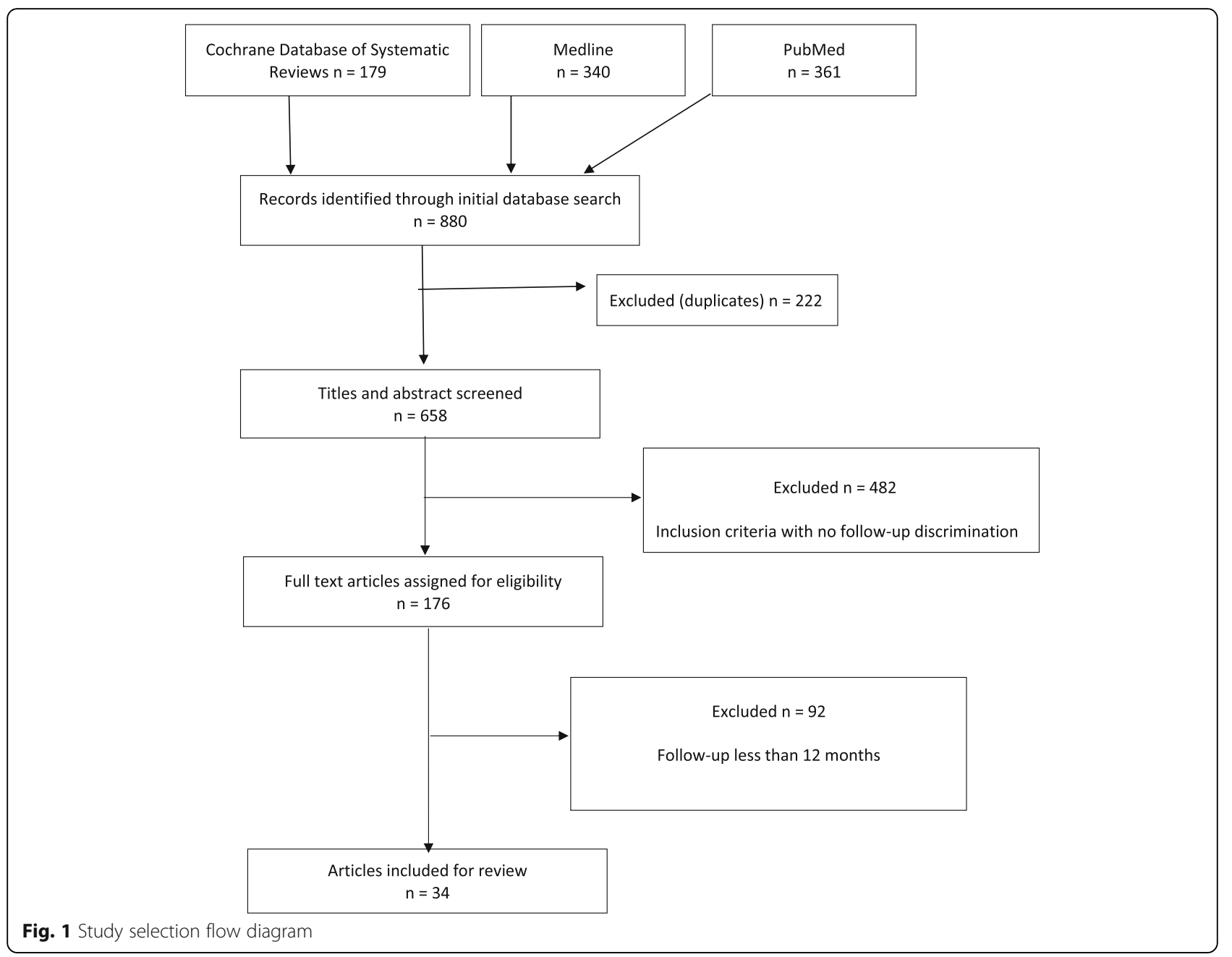

\section{Pharmacological management}

Glucosamine and chondroitin sulphate Three studies $[13,15,17]$ investigated the efficacy of Glucosamine and Chondroitin Sulphate (CS) in 986 patients with KOA for up to 3 years. Two studies demonstrated clinically significant decreases in WOMAC scores. However, no difference in Joint Space Width (JSW) was evident [17]. Minor gastrointestinal side effects such as dyspepsia were present in both the treatment and placebo groups $[13,15,17]$ (Table 1).

Paracetamol One RCT [18] with 571 patients randomised to receive $4 \mathrm{~g} /$ day Paracetamol or Naproxen $750 \mathrm{mg} /$ day demonstrated improvement from baseline in WOMAC score at 6 and 12 months. Minor hepatic, renal and gastrointestinal side effects were reported (Table 1).

Non-steroidal anti-inflammatory drugs (NSAIDs) Two studies [18, 19], including 1233 patients investigated the use of non-steroidal anti-inflammatory drugs (NSAIDs) as treatment for KOA. Naproxen treatment was associated with improvement from baseline in WOMAC score at 6 and 12 months however gastrointestinal bleeding was reported [18]. In contrast, 662 patients with Kellgren-Lawrence(KL) grade 2-3 KOA received Celecoxib as treatment and did not report any improvement in WOMAC from baseline [19]. In addition, gastrointestinal and renal side effects were reported in this group [17] (Table 1).

Opioids No studies for opiate treatment met the inclusion criteria for this analysis.

\section{Injectable}

Intra-articular (IA) corticosteroids Two RCTs [20, 21] with 208 patients used the same treatment protocol of 3 monthly triamcinolone injections for 2-years. The primary outcome measures were WOMAC [21] and cartilage loss on MRI [20]. These studies reported mixed results, while improvement in WOMAC was reported over a 2-year treatment period [21], significantly 


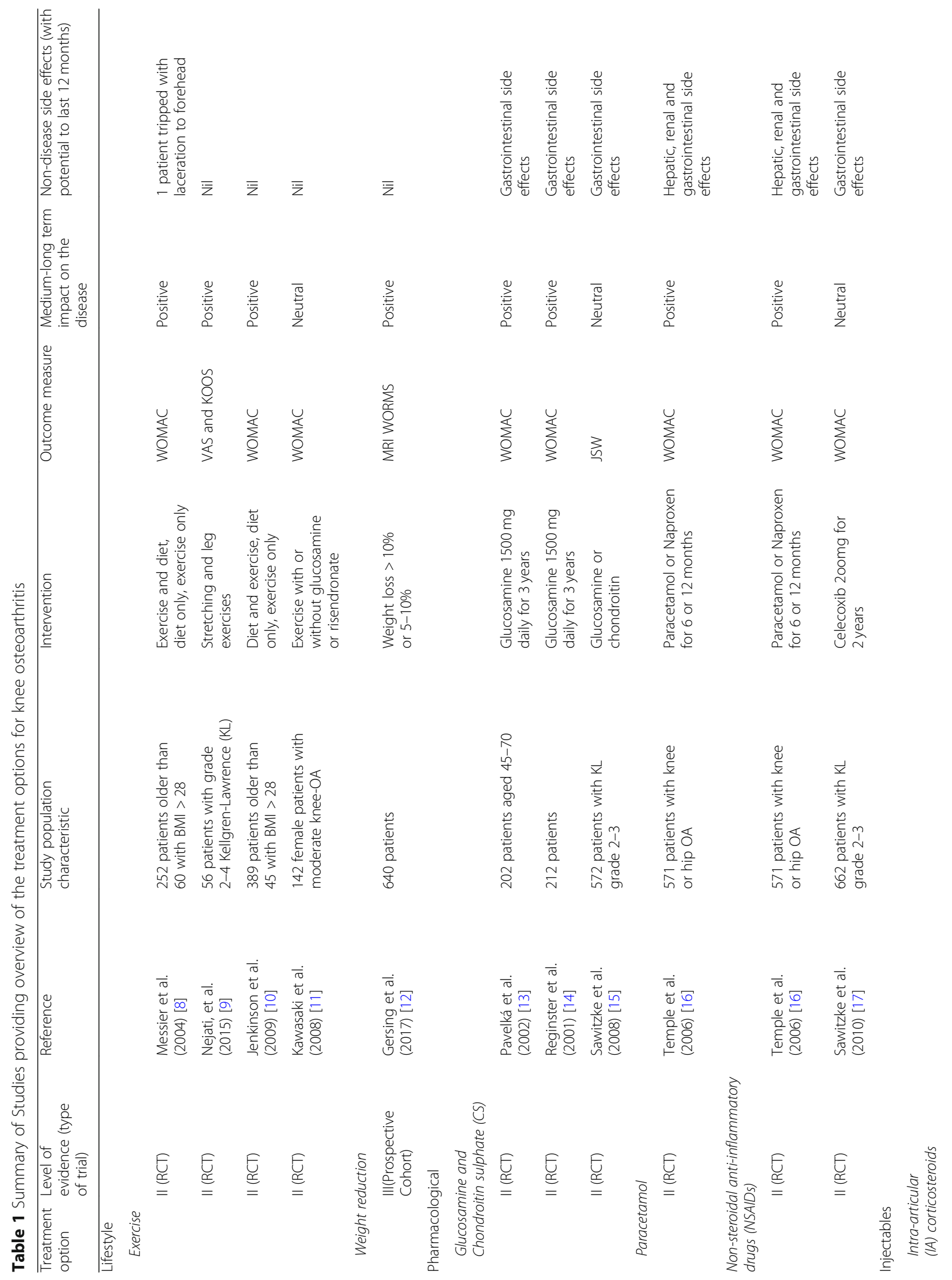




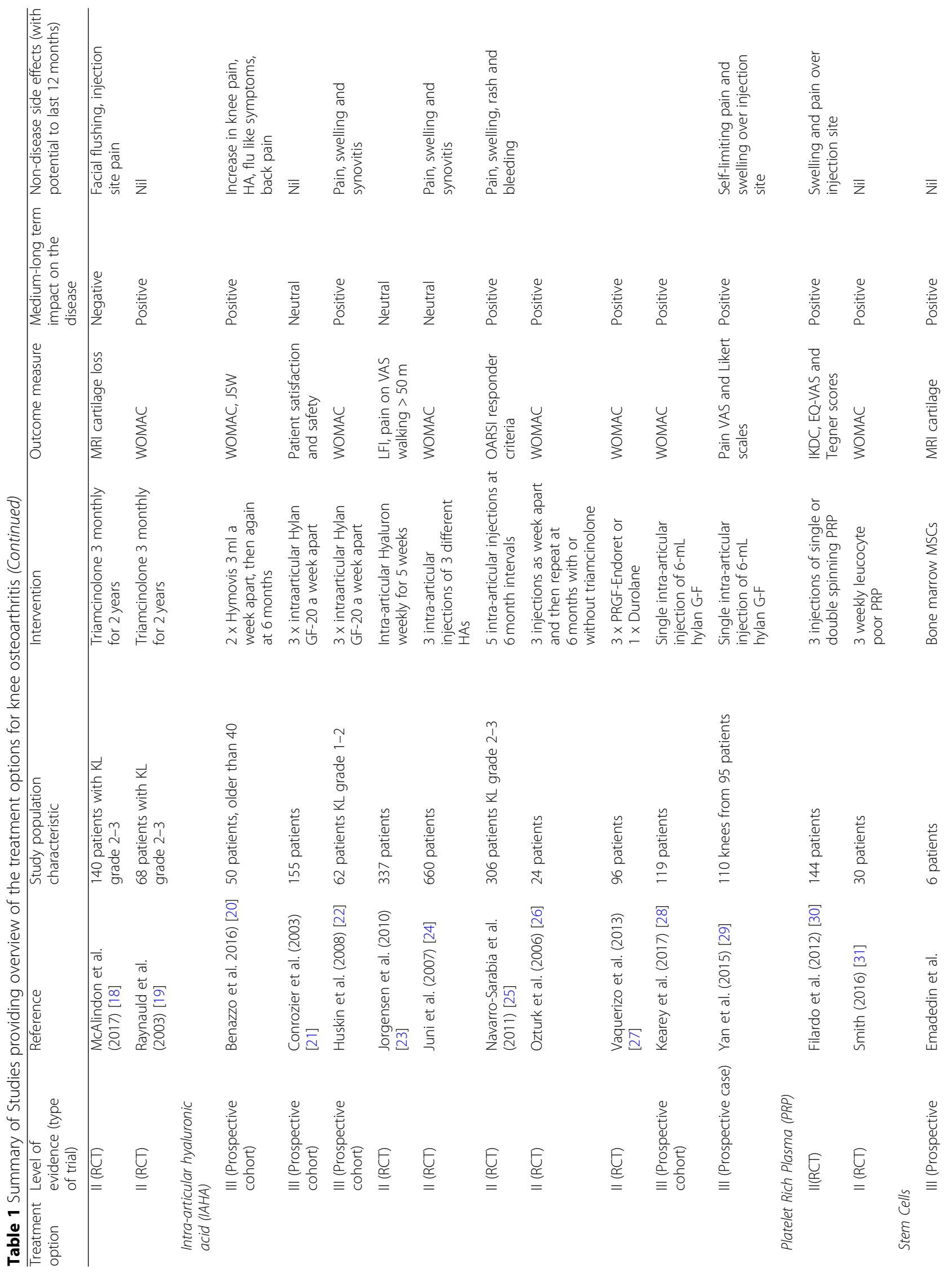




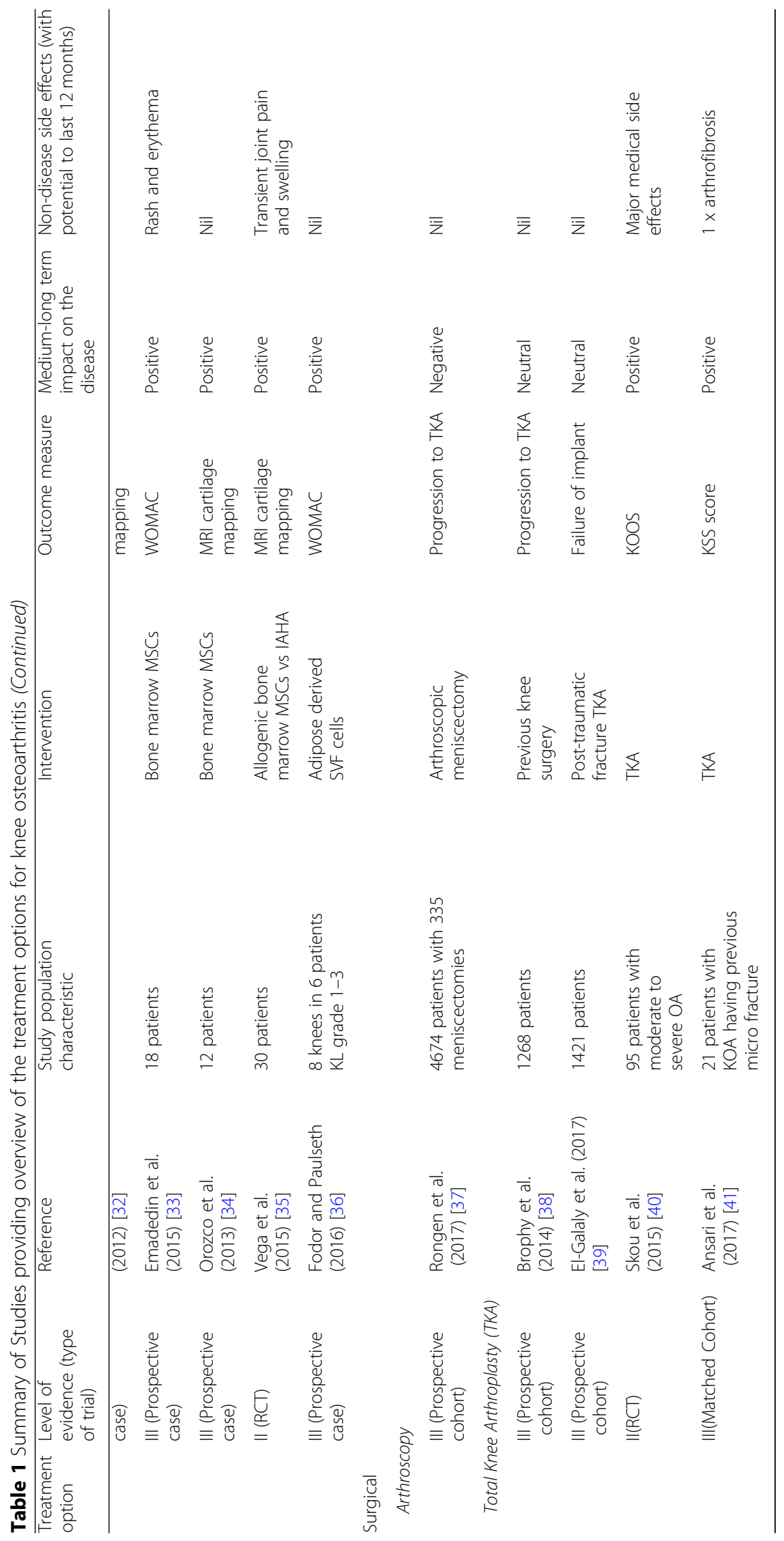


greater cartilage volume loss and no difference in knee pain was reported [20] (Table 1).

Intra-articular hyaluronic acid (IAHA) Ten studies [22-31], including 1904 patients investigated intra-articular hyaluronic acid (IAHAs) as treatment for KOA using WOMAC scores to evaluate the clinical outcome. Seven studies [22, 24, 27-31] demonstrated clinically significant improvement to WOMAC score from baseline while three studies $[23,25,26]$ showed no or insignificant difference in pain and function outcomes. The most common side-effects were self-limiting pain and swelling at the injection site and no major adverse events were reported (Table 1).

Platelet Rich plasma (PRP) Two [32, 33] studies with 174 patients investigated platelet rich plasma (PRP) as treatment for KOA. Both studies reported clinically significant improvement in pain and function with no adverse effects. Pain and swelling were the main side effects (Table 1).

Stem cells Five studies [34-38] with 72 patients investigated stem cells as treatment. Bone marrow mesenchymal stem cells were used in four studies and one study used adipose derived stromal vascular fractions. Improvements in WOMAC $[35,38]$ or MRI cartilage mapping $[34,36,37]$ parameters were reported. Due to small sample size, all of aforementioned studies were under powered, as such results are inconclusive. Side effects included rash, erythema, transient joint pain and swelling (Table 1).

\section{Surgical}

Arthroscopy One study [39] investigated the progression to TKA in patient who underwent meniscectomy because of degenerative meniscal tears. Of the 335 patients who underwent meniscectomy, 63 progressed to a TKA. This was a threefold increase in risk of progression to a TKA compared to an age matched control group (Table 1).

Total knee arthroplasty Four studies [40-43] investigated the long-term effect of various interventions and the progression to TKA. In one study, ninety-five patients with moderate to severe OA showed significant improvement in KOOS score post TKA [42]. However, compared to the control group, the TKA group had a fourfold increase in complications over the 12-month follow-up period. The other studies showed that previous knee surgery including microfracture leads to an increase in progression to a TKA [43] and post-traumatic KOA requiring TKA has a worse outcome than that for non-traumatic OA [41] (Table 1).

\section{Discussion}

This review is the first to synthesise and evaluate the studies which specifically assessed safety of KOA treatment with a minimum follow-up period of a year. This is important because $\mathrm{KOA}$ is diagnosed on average at 55-years of age and typically people live with the disease for about 30-years. Lifestyle modifications (moderate exercise [9-13] and weight loss [12-14]), paracetamol [18], glucosamine [15, 16], IAHA [22-31] and PRP injections [32,33] found to have a low risk of harm and beneficial treatments outcomes at $\geq 12$ months.

Australian general practitioners (GPs) see 6.2 patents with knee-OA for every 1000 consultations [44]. Within the primary care setting, use of nonpharmacological treatments (e.g. exercise) as a first-line management for $\mathrm{KOA}$ is low compared to pharmacological management and the rate of surgical referrals are high [44]. Our results indicate that nonpharmacological treatment such as exercise [10-13] and weight management $[12,14]$ are effective in management of KOA with minimal adverse effects. Primary care settings provide a great platform to support lifestyle interventions effective in treatment and management of KOA. Therefore, weight loss and exercise should be advocated as part of the treatment in all patients due to the low risk of harm, cost effectiveness as well as associated health benefits. It is important to allocate resources and invest in supporting GPs and other primary health care providers to provide lifestyle interventions to treat and manage KOA at the community level.

Opiates continue to be used to manage pain associated with $\mathrm{KOA}$, irrespective of a large body of evidence questioning the benefits of opioid use [45]. We were unable to evaluate evidence on the effectiveness and safety of long-term ( $\geq 12$ months) opioid therapy for KOA because no studies met the inclusion criteria as the follow-ups of those studies considering safety were $<6$ months. This is a concern and a limitation of the available evidence relating to $\mathrm{KOA}$ management. A recent systematic review into chronic pain management found that there is insufficient evidence to support the effectiveness of long-term opioid therapy [45]. Opioids provide effective analgesia however, benefits are limited by frequent side effects such as nausea (30\%) and vomiting (13\%), constipation (23\%), dizziness (20\%) and somnolence (18\%) [46]. Long-term opioid use increases the risk of abuse and addiction [45]. Rates of iatrogenic addiction range from 1 to $26 \%$ and have to be carefully delineated from misuse or abuse a more conservative diagnosis of addiction is present in around $8 \%$ of those prescribed long-term opiates for chronic pain [47]. In the United States, opioids were prescribed to $15.9 \%$ of patients with KOA [48] and there has been a significant increase in opioid prescriptions for persons with KOA [49]. Australia is following a similar 
pattern [50] and opioid overuse is currently dominating public debate. In the first instance, opioids should be prescribed for a short-term trial basis, as part of a multimodal strategy, with regular review of treatment response and adverse effects. This treatment should perhaps be reserved for those who are unable to have other treatments like TKA because of multiple medical comorbidities.

In terms of other oral analgesics, paracetamol has a more favourable safety profile than NSAIDS but the risk of liver toxicity is not negligible on the recommended dose of up to $4 \mathrm{~g} /$ day. Treatment with high dose paracetamol $(>3 \mathrm{~g} /$ day $)$ is associated with a greater risk of hospitalisation due to gastrointestinal (GI) perforation, ulceration or bleeding compared to $3 \mathrm{~g} /$ day [51]. NSAIDS generally provide superior pain relief compared to paracetamol but with increased safety considerations. For example, long-term use of NSAIDs medications are associated with increased risk of complications such as gastrointestinal [18, 19] and renal [19] complications. Indeed, oral NSAIDs increase in the risk of upper gastrointestinal complications, including peptic ulcer perforation, obstruction, and bleeding by three- to five-fold. The use of selective COX2 inhibitors like celecoxib has been researched extensively to decrease the gastrointestinal risk. However, a recent RCT reported that treatment with celecoxib increased the risk of recurrent GI bleeding by $9 \%$ in very high-risk patients [52]. In addition, prolonged NSAID use is associated with adverse cardiovascular events in the short and long term [53-55].

There are risks associated with injectable treatments such as cortisone, IAHA and PRP. Recurrent cortisone injections into the knee decrease cartilage volume [20]. In addition, cortisone injections into the knee before surgery increases the risk of subsequent infection in people who undergo TKA [56]. The incidence of serious infectious complications following cortisone injections into the knee ranges widely, and may be as high as 1 in 3000 in high-risk patients [57]. Systemic effects reported include transient hyperglycemia, warmth or flushing of the skin and cushingoid appearance if treatment is too frequent. Local reactions include subcutaneous or cutaneous atrophy and capsular periarticular calcification [57].

Adverse events associated with IAHAs include severe acute inflammatory reactions (SAIR) or pseudo septic reactions. Whilst $2-8 \%$ of patients who received the cross-linked hylan G-F 20 preparation reported a SAIR [58], SAIRs have not been reported after injection of any of the natural IAHAs. Despite similarities, IAHA products should not be treated as a group, as there are differences in IAHA products that influence both efficacy and safety. A recent Cochrane review did not report any major safety issues associated with IAHA except local adverse events such as transient pain and swelling at the injection site [59].

Surgical procedures are associated with risk of infection, bleeding and deep vein thrombosis (DVT). Since there is a tendency for high rates of surgical referrals among Australian GPs [44], it is important to avoid unnecessary surgeries such as knee arthroscopy for degenerative menisci, particularly because that progression to a TKA may be greater after an arthroscopy [39]. In 2014, there were 54, 277 knee replacements performed in Australia [3]. Compared to other Organisation for Economic Co-operation and Development countries, Australia has a higher than average TKA rate. It is generally presumed that the increase in population ageing and obesity rates are responsible for the observed increase in TKA rates. In Australia, 63.4\% adults are overweight or obese [60] and 16\% Australians are aged 65 years and over [61]. In addition, $45 \%$ of the population does not meet physical acitivity reccomendations [60]. Therefore, as discussed above it is important that primary care practitioners use lifestyle modifications such as exercise and weight management as first lines of treatment given their associated benefits in the management of KOA as well as to reduce the burden on the Australian healthcare system associated with inactivity related complications.

Findings from this review indicate that most of the commonly used KOA treatments (based on short-term improvements or traditional treatment protocols) might have harmful effects in the longer-term. It can be hypothesised that some of the recent increase in rates of TKAs observed in Australia might be due to iatrogenic worsening of KOA. The increasing rates of TKA have been previously explained by better availability of the procedure, ageing and increased obesity. However, long-term worsening of KOA outcomes from the overuse of knee arthroscopy, cortisone injections, NSAIDs and opiates, might have contributed to worsening of clinical outcome for KOA patients. Given that on average patents with KOA live 30-years with their condition, long-term safety and disease progression needs to be considered as a vital aspect of treatment regimen than short-term symptom relief. Perspectives on KOA management need to shift from a short-term viewpoint to a long-term one, with improved clinical acumen in prescribing and managing the risks associated with the currently available treatments options.

\section{Strengths and limitations}

High methodological rigour was maintained by developing an a priori study protocol per PRISMA guidelines [5]. This review, therefore, provides a reliable overview of current data pertaining to long term efficacy and safety of KOA treatments. However, by the standards of a systemic review, another author should have screened the articles and this is a limitation to the search strategy. 
The number of studies included is limited as only studies addressing the safety of KOA treatment with $\geq 12$ months of follow-up were included. Thus, short term benefits and studies which did not specifically assess safety were excluded. This limitation is acknowledged as there are good studies that look at short and long-term outcomes including side effects of treatment that don't specifically discuss safety that have been omitted by the search strategy. Furthermore, a complete picture of a treatment should ideally consider both short and long term. However, given patients typically live approximately 30 -years with the disease, it is important to develop an evidence-based understanding of the long-term harms of treatments is important to ensure patient safety.

\section{Conclusion}

KOA management algorithms should shift from a short-term viewpoint to a long-term one, with a focus on the long-term safety and efficacy of currently available treatment options, to enable improved clinical acumen in managing KOA.

Many commonly used KOA treatments have harmful effects in the longer-term. NSAIDs increase the risk of gastrointestinal, renal and cardiovascular side effects. We could locate no evidence regarding the risks of long-term harm (addiction, overdose and death) attributable to opiate treatments in patients with KOA. Surgery is associated with risks of medical complications such as deep vein thrombosis and infection however in late-stage disease can be justified by the efficacy of joint replacement; whilst use of knee arthroscopies cannot be justified.

Exercise and weight loss are both safe and effective for long-term treatment and these should be advocated in all patients. To supplement these lifestyle modifications, the judicious use of analgesia, intra-articular injections of cortisone and consideration of hyaluronic acids and platelet-rich plasma are recommended for symptomatic relief in KOA.

\section{Appendix 1}

Table 2 Narrative review search strategy

\begin{tabular}{|c|c|c|c|c|}
\hline \multicolumn{2}{|l|}{ Database } & \multirow{2}{*}{$\begin{array}{l}\text { Search terms } \\
\text { TX (Osteoarthritis, knee) }\end{array}$} & \multirow{2}{*}{$\begin{array}{l}\text { Search number } \\
1\end{array}$} & \multirow{2}{*}{$\begin{array}{l}\text { Applied filters } \\
\text { Human } \\
\text { Language filter (English) }\end{array}$} \\
\hline $\begin{array}{l}\text { Cochrane Database of } \\
\text { Systematic Reviews }\end{array}$ & Medical condition terms & & & \\
\hline & Treatment terms AND safety & $\begin{array}{l}\text { Treatments OR Diet therapy[Mesh] OR } \\
\text { Drug therapy[Mesh] OR Rehabilitation[Mesh] } \\
\text { OR Surgery [Mesh] OR Therapy AND Safety }\end{array}$ & 2 & \\
\hline & $\begin{array}{l}\text { Medical condition terms AND } \\
\text { treatment terms AND safety }\end{array}$ & 1 AND 2 & 3 & \\
\hline \multirow[t]{3}{*}{ Medline } & Treatment terms & $\begin{array}{l}\text { TX (osteoarthritis OR degenerative arthritis } \\
\text { OR degenerative joint disease) }\end{array}$ & 1 & $\begin{array}{l}\text { Human Language filter } \\
\text { (English) }\end{array}$ \\
\hline & Treatment terms AND safety & $\begin{array}{l}\text { Treatment OR Surgery OR Knee replacement } \\
\text { OR TKR OR knee arthroscopy OR Tibial } \\
\text { Osteotomy OR NSAIDs OR Opiates OR } \\
\text { Paracetamol OR Glucosamine OR Cortisone } \\
\text { OR Hyaluronan Gel OR PRP OR Stem Cells } \\
\text { OR Exercise Program OR Weight Loss AND } \\
\text { Safety }\end{array}$ & 2 & \\
\hline & $\begin{array}{l}\text { Medical condition terms AND } \\
\text { treatment terms AND safety }\end{array}$ & 1 AND 2 & 3 & \\
\hline \multirow[t]{3}{*}{ PubMed } & Medical condition terms & $\begin{array}{l}\text { "Osteoarthritis, Knee"[Mesh] OR TITLE-ABS-KEY } \\
\text { (osteoarthritis OR degenerative arthritis OR } \\
\text { degenerative joint disease) }\end{array}$ & 1 & $\begin{array}{l}\text { Human Language filter } \\
\text { (English) }\end{array}$ \\
\hline & Treatment terms AND safety & $\begin{array}{l}\text { "Osteoarthritis, Knee/diet therapy"[Mesh] OR } \\
\text { "Osteoarthritis, Knee/drug therapy"[Mesh] OR } \\
\text { "Osteoarthritis, Knee/prevention and control" } \\
\text { [Mesh] OR OR "Osteoarthritis, Knee/rehabilitation" } \\
\text { [Mesh] OR "Osteoarthritis, Knee/surgery"[Mesh] } \\
\text { OR "Osteoarthritis, Knee/therapy"[Mesh] OR } \\
\text { TITLE-ABS-KEY (Treatment OR Surgery OR Knee } \\
\text { replacement OR TKR OR knee arthroscopy OR } \\
\text { NSAIDs OR Paracetamol OR Glucosamine OR } \\
\text { Opiates OR Cortisone OR PRP OR Stem Cells } \\
\text { OR Hyaluronan Gel OR Exercise Program) AND } \\
\text { "Safety" [MeSH] }\end{array}$ & 2 & \\
\hline & 1 AND 2 & 1 AND 2 & 3 & \\
\hline
\end{tabular}




\section{Appendix 2}

Table 3 Inclusion/exclusion criteria for the risks and harms associated with commonly used treatment for knee osteoarthritis literature search

\begin{tabular}{|c|c|c|c|}
\hline & Inclusion criteria & Exclusion criteria & Rationale for this criteria \\
\hline $\begin{array}{l}\text { Publication } \\
\text { type }\end{array}$ & $\begin{array}{l}\text { Peer-reviewed original research articles, } \\
\text { systematic reviews and meta-analysis only }\end{array}$ & $\begin{array}{l}\text { Non-peer-reviewed articles, newspapers, } \\
\text { opinion pieces, editorials, commentaries } \\
\text { and letters to the editor. Conference } \\
\text { proceedings/abstracts. Book chapters. } \\
\text { Downs and Black [7] quality score }>13\end{array}$ & $\begin{array}{l}\text { The aim of this review was to investigate } \\
\text { the risks and harms associated with } \\
\text { commonly used treatment for knee } \\
\text { osteoarthritis. For reasons of practicality, it } \\
\text { was deemed acceptable to include only } \\
\text { studies published in peer-reviewed journals. }\end{array}$ \\
\hline Language & English language & Non-English & $\begin{array}{l}\text { For reasons of practicality, it was deemed } \\
\text { acceptable to include only studies } \\
\text { published in English. }\end{array}$ \\
\hline Population & $\begin{array}{l}\text { Knee osteoarthritis in patients 18-years } \\
\text { and older }\end{array}$ & $\begin{array}{l}\text { Knee osteoarthritis in patients 17-years } \\
\text { and younger }\end{array}$ & $\begin{array}{l}\text { Average age of knee osteoarthritis } \\
\text { diagnosis is } 55 \text {-years and typically people } \\
\text { live about } 30 \text {-years with the disease. }\end{array}$ \\
\hline Intervention & $\begin{array}{l}\text { Operative and non-operative management } \\
\text { of knee osteoarthritis treatments treatments } \\
\text { listed in the Australian Clinical Care } \\
\text { Standard [5] and/or Therapeutic Guidelines: } \\
\text { Rheumatology [6] and specifically } \\
\text { addressed safety of the treatments; }\end{array}$ & $\begin{array}{l}\text { Operative and non-operative management } \\
\text { of knee osteoarthritis not listed in the } \\
\text { Australian Clinical Care Standard [5] and/or } \\
\text { Therapeutic Guidelines: Rheumatology [6]. }\end{array}$ & $\begin{array}{l}\text { Commonly accepted treatments were } \\
\text { sought out and the authors decided upon } \\
\text { treatments listed in Australian Clinical Care } \\
\text { Standard [5] and/or Therapeutic Guidelines: } \\
\text { Rheumatology [6]. }\end{array}$ \\
\hline $\begin{array}{l}\text { Outcome } \\
\text { measures }\end{array}$ & $\begin{array}{l}\text { Studies specifically addressed safety of the } \\
\text { treatments with } \geq 12 \text { months of follow-up. } \\
\text { Long-term effect of a treatment could be } \\
\text { either: (1) Positive OR negative effect of } \\
\text { index treatment vs comparison treatment } \\
\text { in any trial persisting at } \geq 12 \text { months; or ( } 2 \text { ) } \\
\text { Positive OR negative effect of index } \\
\text { treatment vs comparison treatment in any } \\
\text { trial showing significant change in any } \\
\text { objective disease indicator (e.g. cartilage } \\
\text { thickness on magnetic resonance imaging } \\
\text { (MRI) or X-ray) at } \geq 12 \text { months; or (3) Effect } \\
\text { of index treatment showing significantly } \\
\text { increased OR reduced risk of progression to } \\
\text { TKA; or (4) Significant increase in side-effect } \\
\text { or harm related to treatment with a } \\
\text { potential for ongoing harm from this } \\
\text { condition to persist beyond } 12 \text { months. }\end{array}$ & $\begin{array}{l}\text { Short-term effects of osteoarthritis } \\
\text { treatments. Side effects and adverse effects } \\
\text { were not included in this review as they } \\
\text { are typically short-term issues (e.g. allergic } \\
\text { rash, post-procedure soreness). }\end{array}$ & $\begin{array}{l}\text { The primary outcomes of interest for this } \\
\text { review was to describe the long-term } \\
\text { effects of the knee osteoarthritis treatments. } \\
\text { As there is no curative treatment for OA } \\
\text { currently, treatments are aimed at reducing } \\
\text { pain and improving function. The } \\
\text { prevalence of osteoarthritis increases with } \\
\text { age, particularly after the age of 55-years } \\
\text { such that the average person lives } 30 \text {-years } \\
\text { with knee OA. Therefore, it is important to } \\
\text { appraise the long-term effects of knee OA } \\
\text { treatment. }\end{array}$ \\
\hline
\end{tabular}

\section{Additional file}

Additional file 1: Tables S1. Methodological quality ratings of reviewed papers. (DOCX $27 \mathrm{~kb})$

\begin{abstract}
Abbreviations
CS: Chondroitin Sulphate; DVT: Deep Vein Thrombosis; Gl: Gastrointestinal; GPS: General Practitioners; IA: Intra-articular; IAHA: Intra-articular Hyaluronic Acid; JSW: Joint Space Width; KL: Kellgren Lawrence; KOA: Knee OsteoarthritisPRPPlatelet Rich Plasma; KOOS: Knee injury and Osteoarthritis Outcome Score; MRI: Magnetic Resonance Imaging; NSAIDs: Non-steroidal Anti-inflammatories; OA: Osteoarthritis; RCT: Randomised Controlled Trial; TKA: Total Knee Arthroplasty; VAS: Visual Analogue Scale; WOMAC: Western
\end{abstract} Ontario and McMaster Universities Osteoarthritis Index
Availability of data and materials

All data generated or analysed during this study are included in this published article [and its supplementary information files].

\section{Authors' contributions}

JC participated in study design, collection of the data, the analysis and interpretation of the data, and the drafting of the article. JF participated in the study design, drafting the article and critical revisions of the manuscript and provided final approval of the article. NKPP participated in the study design, drafting the article and critical revisions of the manuscript. JO participated in the study design, drafting the article and critical revisions of the manuscript. All authors have read and approved the manuscript.

Ethics approval and consent to participate Not applicable

\section{Consent for publication}

Not applicable.

Competing interests

The authors' declare that they have no competing interests. 


\section{Publisher's Note}

Springer Nature remains neutral with regard to jurisdictional claims in published maps and institutional affiliations.

\section{Author details \\ ${ }^{1}$ Australasian College of Sport and Exercise Physicians, 257 Collins Street, Melbourne, VIC 3000, Australia. 'Division of Physiotherapy, Department of Medical and Health Science, Linköping University, Linköping, Sweden. ${ }^{3}$ University of Melbourne, Melbourne, Australia. ${ }^{4}$ Sports Medicine Professionals, University of Melbourne, Level 7, Alan Gilbert Bdg, 161 Barry Street, Melbourne, VIC 3010, Australia. ${ }^{5}$ School of Public Health, University of Sydney, Sydney, NSW, Australia.}

\section{Received: 26 November 2018 Accepted: 24 March 2019 Published online: 09 April 2019}

\section{References}

1. March LM, Bagga H. Epidemiology of osteoarthritis in Australia. Med J Aust. 2004;180(5 Suppl):S6-10.

2. Australian Institute of Health and Welfare (AUS). Osteoarthritis. Canberra: Australian Institute of Health and Welfare; 2016. Available from https://www. aihw.gov.au/reports/chronic-musculoskeletal-conditions/osteoarthritis/ contents/what-is-osteoarthritis. [cited 15 August 2017]

3. Losina E, Weinstein AM, Reichmann WM, Burbine SA, Solomon DH, Daigle $M E$, et al. Lifetime risk and age at diagnosis of symptomatic knee osteoarthritis in the US. Arthritis Care Res (Hoboken). 2013;65(5):703-11.

4. Australian Orthopaedic Association (AUS). Lay summary 2015 annual report hip and knee replacement: suppliment report 2015. Sydney: Australian Orthopaedic Association; 2015. Available from https://aoanjrr.sahmri.com/ documents/10180/217745/Hip+and+Knee+Arthroplasty. [cited 15 August 2017]

5. Moher D, Shamseer $L$, Clarke $M$, et al. Preferred reporting items for systematic review and meta-analysis protocols (PRISMA-P) 2015 statement. Syst Rev. 2015;4(1):1-9.

6. Moher D, Tricco A. Issues related to the conduct of systematic reviews: a focus on the nutrition field. Am J Clin Nutr. 2008;88(5):1191-9.

7. Australian Commission on Safety and Quality in Health Care (AUS) Osteoarthritis of the knee clinical care standard. Sydney: Australian commission on safety and Quality in Health Care; 2017. Available from: https://www.safetyandquality.gov.au/wp-content/uploads/2018/04/ Osteoarthritis-of-the-knee-Clinical-Care-Standard.pdf. [cited 2 July 2017]

8. Rheumatology Expert Group (AUS). Therapeutic guidelines: rheumatology version 3. Melbourne: therapeutic guidelines limited.; 2017 . Available from https://www.ckn.org.au/content/therapeutic-guidelines-etg-completerheumatology-3. [cited 2 July 2017]

9. Downs $\mathrm{S}$, Black $N$. The feasibility of creating a checklist for the assessment of the methodological quality both of randomised and non-randomised studies of health care interventions. J Epidemio Community Health. 1998;52(6):377-84.

10. Messier S, Loeser R, Miller $\mathrm{G}$, et al. Exercise and dietary weight loss in overweight and obese older adults with knee osteoarthritis: the arthritis, diet, and activity promotion trial. Arthritis Rheum. 2004;50(5):1501-10.

11. Nejati P, Farzinmehr A, Moradi-Lakeh M. The effect of exercise therapy on knee osteoarthritis: a randomized clinical trial. Med J Islam Repub Iran. 2015;29:186

12. Jenkinson C, Doherty M, Avery J, et al. Effects of dietary intervention and quadriceps strengthening exercises on pain and function in overweight people with knee pain: randomised controlled trial. BMJ. 2009;339:b3170.

13. Kawasaki $\mathrm{T}$, Kurosawa $\mathrm{H}$, Ikeda $\mathrm{H}$, et al. Additive effects of glucosamine or risedronate for the treatment of osteoarthritis of the knee combined with home exercise: a prospective randomized 18-month trial. J Bone Miner Metab. 2008;26(3):279-87.

14. Gersing A, Schwaiger B, Nevitt M, et al. Is weight loss associated with less progression of changes in knee articular cartilage among obese and overweight patients as assessed with MR imaging over 48 months? Data from the osteoarthritis initiative. Radiol. 2017:284(2):508-20.

15. Pavelká K, Gatterová J, Olejarová M, et al. Glucosamine sulfate use and delay of progression of knee psteoarthritis. Arch Intern Med. 2002;162(18):2113.

16. Reginster J, Deroisy R, Rovati L, et al. Long-term effects of glucosamine sulphate on osteoarthritis progression: a randomised, placebo-controlled clinical trial. Lancet. 2001;357(9252):251-6.
17. Sawitzke A, Shi H, Finco M, et al. The effect of glucosamine and/or chondroitin sulfate on the progression of knee osteoarthritis: a report from the glucosamine/chondroitin arthritis intervention trial. Arthritis Rheum. 2008:58(10):3183-91.

18. Temple A, Benson G, Zinsenheim J, et al. Multicenter, randomized, doubleblind, active-controlled, parallel-group trial of the long-term (6-12 months) safety of acetaminophen in adult patients with osteoarthritis. Clin Ther. 2006;28(2):222-35.

19. Sawitzke A, Shi H, Finco M, et al. Clinical efficacy and safety of glucosamine, chondroitin sulphate, their combination, celecoxib or placebo taken to treat osteoarthritis of the knee: 2-year results from GAIT. Ann Rheum Dis. 2010; 69(8):1459-64

20. McAlindon T, LaValley M, Harvey W, et al. Effect of intra-articular triamcinolone vs saline on knee cartilage volume and pain in patients with knee osteoarthritis: a randomized clinical trial. JAMA. 2017;317(19):1967-75.

21. Raynauld J, Buckland-Wright C, Ward R, et al. Safety and efficacy of long-term intraarticular steroid injections in osteoarthritis of the knee: a randomized, double-blind, placebo-controlled trial. Arthritis Rheum. 2003:48(2):370-7.

22. Benazzo F, Perticarini L, Padolino A, et al. A multi-Centre, open label, longterm follow-up study to evaluate the benefits of a new viscoelastic hydrogel (Hymovis(R)) in the treatment of knee osteoarthritis. Eur Rev Med Pharmacol Sci. 2016;20(5):959-68.

23. Conrozier T, Mathieu P, Schott A, et al. Factors predicting long-term efficacy of Hylan GF-20 viscosupplementation in knee osteoarthritis. Joint Bone Spine. 2003;70(2):128-33.

24. Huskin J, Vandekerckhove B, Delince $P$, et al. Multicentre, prospective, open study to evaluate the safety and efficacy of hylan G-F 20 in knee osteoarthritis subjects presenting with pain following arthroscopic meniscectomy. Knee Surg Sports Traumatol Arthrosc. 2008;16(8):747-52

25. Jorgensen A, Stengaard-Pedersen K, Simonsen O, et al. Intra-articular hyaluronan is without clinical effect in knee osteoarthritis: a multicentre, randomised, placebo-controlled, double-blind study of 337 patients followed for 1 year. Ann Rheum Dis. 2010:69(6):1097-102.

26. Juni $P$, Reichenbach $S$, Trelle $S$, et al. Efficacy and safety of intraarticular hylan or hyaluronic acids for osteoarthritis of the knee: a randomized controlled trial. Arthritis Rheum. 2007;56(11):3610-9.

27. Navarro-Sarabia F, Coronel P, Collantes E, et al. A 40-month multicentre, randomised placebo-controlled study to assess the efficacy and carry-over effect of repeated intra-articular injections of hyaluronic acid in knee osteoarthritis: the AMELIA project. Ann Rheum Dis. 2011;70(11):1957-62

28. Ozturk C, Atamaz F, Hepguler $S$, et al. The safety and efficacy of intraarticular hyaluronan with/without corticosteroid in knee osteoarthritis: 1-year, single-blind, randomized study. Rheumatol Int. 2006;26(4):314-9.

29. Vaquerizo V, Plasencia M, Arribas I, et al. Comparison of intra-articular injections of plasma rich in growth factors (PRGF-Endoret) versus Durolane hyaluronic acid in the treatment of patients with symptomatic osteoarthritis: a randomized controlled trial. Arthroscopy. 2013:29(10):1635-43.

30. Kearey P, Popple A, Warren J, et al. Improvement in condition-specific and generic quality of life outcomes in patients with knee osteoarthritis following single-injection Synvisc: results from the LOBRAS study. Curr Med Res Opin. 2017;33(3):409-19.

31. Yan C, Chan W, Yuen W, et al. Efficacy and safety of hylan G-F 20 injection in treatment of knee osteoarthritis in Chinese patients: results of a prospective, multicentre, longitudinal study. Hong Kong Med J. 2015;21(4):327-32.

32. Filardo $G$, Kon E, Pereira Ruiz M, et al. Platelet-rich plasma intra-articular injections for cartilage degeneration and osteoarthritis: single- versus double-spinning approach. Knee Surg Sports Traumatol Arthrosc. 2012; 20(10):2082-91.

33. Smith P. Intra-articular autologous conditioned plasma injections provide safe and efficacious treatment for knee osteoarthritis: an FDA-sanctioned, randomized, double-blind, placebo-controlled clinical trial. Am J Sports Med. 2016;44(4):884-91

34. Emadedin M, Aghdami N, Taghiyar $\mathrm{L}$, et al. Intra-articular injection of autologous mesenchymal stem cells in six patients with knee osteoarthritis. Arch Iran Med. 2012;15(7):422-8.

35. Emadedin M, Ghorbani Liastani M, Fazeli R, et al. Long-term follow-up of intra-articular injection of autologous mesenchymal stem cells in patients with knee, ankle, or hip osteoarthritis. Arch Iran Med. 2015;18(6):336-44. 
36. Orozco L, Munar A, Soler R, et al. Treatment of knee osteoarthritis with autologous mesenchymal stem cells: a pilot study. Transplantation. 2013;95(12):1535-41.

37. Vega A, Martin-Ferrero M, Del Canto F, et al. Treatment of knee osteoarthritis with allogeneic bone marrow mesenchymal stem cells: a randomized controlled trial. Transplantation. 2015;99(8):1681-90.

38. Fodor P, Paulseth S. Adipose derived stromal cell (ADSC) injections for pain management of osteoarthritis in the human knee joint. Aesthet Surg J. 2016;36(2):229-36.

39. Rongen J, Rovers M, van Tienen T, et al. Increased risk for knee replacement surgery after arthroscopic surgery for degenerative meniscal tears: a multicenter longitudinal observational study using data from the osteoarthritis initiative. Osteoarthr Cartil. 2017;25(1):23-9.

40. Brophy R, Gray B, Nunley R, et al. Total knee arthroplasty after previous knee surgery: expected interval and the effect on patient age. J Bone Joint Surg Am. 2014;96(10):801-5.

41. El-Galaly A, Haldrup S, Pedersen A, et al. Increased risk of early and medium-term revision after post-fracture total knee arthroplasty. Acta Orthop. 2017;88(3):263-8.

42. Skou $\mathrm{S}$, Roos $\mathrm{E}$, Laursen $\mathrm{M}$, et al. A randomized controlled trial of total knee replacement. N Engl J Med. 2015:373(17):1597-606.

43. Ansari M, Pareek A, Johnson N, et al. Clinical outcome of total knee arthroplasty after prior microfracture: a matched cohort study. Orthopedics. 2017:40(3):e473-8

44. Brand CA, Harrison C, Tropea J, et al. Management of osteoarthritis in general practice in Australia. Arthritis Care Res. 2014;66(4):551-8.

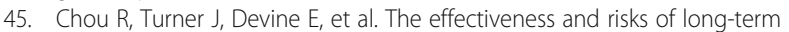
opioid therapy for chronic pain: a systematic review for a national institutes of health pathways to prevention workshop effectiveness and risks of longterm opioid therapy for chronic pain. Ann Intern Med. 2015;162(4):276-86.

46. Furlan A, Sandoval J, Mailis-Gagnon A, et al. Opioids for chronic noncancer pain: a meta-analysis of effectiveness and side effects. CMAJ. 2006;174(11):1589-94.

47. Volkow N, McLellan A. Opioid abuse in chronic pain-misconceptions and mitigation strategies. N Engl J Med. 2016;374(13):1253-63.

48. DeMik D, Bedard N, Dowdle $\mathrm{S}$, et al. Are we still prescribing opioids for osteoarthritis? J Arthroplast 2017. S0883-5403(17)30666-30666.

49. Wright E, Katz J, Abrams S, et al. Trends in prescription of opioids from 2003-2009 in persons with knee osteoarthritis. Arthritis Care Res. 2014;66(10):1489-95.

50. Basedow M, Williams $H$, Shanahan $E$, et al. Australian GP management of osteoarthritis following the release of the RACGP guideline for the non-surgical management of hip and knee osteoarthritis. BMC Res Notes. 2015:8:536

51. Bruyere $\mathrm{O}$, Cooper C, Pelletier J, et al. A consensus statement on the European Society for Clinical and Economic Aspects of osteoporosis and osteoarthritis (ESCEO) algorithm for the management of knee osteoarthritisfrom evidence-based medicine to the real-life setting. Semin Arthritis Rheum. 2016:45(4 Suppl):S3-11.

52. Cutolo M, Berenbaum F, Hochberg M, et al. Commentary on recent therapeutic quidelines for osteoarthritis. Semin Arthritis Rheum. 2015:44(6):611-7.

53. Sondergaard $K$, Weeke $P$, Wissenberg $M$, et al. Non-steroidal antiinflammatory drug use is associated with increased risk of out-of-hospital cardiac arrest: a nationwide case-time-control study. Eur Heart J Cardiovasc Pharmacother. 2017;3(2):100-7.

54. Bhatt D, Scheiman J, Abraham N, et al. ACCF/ACG/AHA 2008 expert consensus document on reducing the gastrointestinal risks of antiplatelet therapy and NSAID use: a report of the American College of Cardiology Foundation task force on clinical expert consensus documents. J Am Coll Cardiol. 2008:52(18):1502-17.

55. Bally M, Dendukuri N, Rich B, et al. Risk of acute myocardial infarction with NSAIDs in real world use: bayesian meta-analysis of individual patient data. BMJ. 2017;357:j1909.

56. Cancienne J, Werner B, Luetkemeyer $L$, et al. Does timing of previous intraarticular steroid injection affect the post-operative rate of infection in total knee arthroplasty? J Arthroplast. 2015;30(11):1879-82

57. McGarry J, Daruwalla Z. The efficacy, accuracy and complications of corticosteroid injections of the knee joint. Knee Surg Sports Traumato Arthrosc. 2011;19(10):1649-54.

58. Aggarwal A, Sempowski I. Hyaluronic acid injections for knee osteoarthritis. Systematic review of the literature. Can Fam Physician. 2004;50:249-56.
59. Bellamy N, Campbell J, Robinson V, et al. Viscosupplementation for the treatment of osteoarthritis of the knee. Cochrane Database Syst Rev. 2006;2:CD005321

60. Australian Bureau of Statistics (AUS). 4364.0.55.001 - National Health Survey: first results, 2014-15. Canberra: Australian Bureau of Statistics; 2016. Available from: https://www.ausstats.abs.gov.au/ausstats/subscriber. nsf/0/CDA852A349B4CEE6CA257F150009FC53/\$File/ national\%20health\%20survey\%20first\%20results,\%202014-15.pdf. [cited 12 August 2017]

61. Australian Bureau of Statistics (AUS). Snapshot of Australia: 2016 Census data summary. Canberra: Australian Bereau of Statistics; 2017. Available from: https://www.abs.gov.au/ausstats/abs@.nsf/Lookup/by\%20Subject/2071. 0 2016 Main\%20Features Ageing\%20Population 14. [cited 12 August 2017]
Ready to submit your research? Choose BMC and benefit from:

- fast, convenient online submission

- thorough peer review by experienced researchers in your field

- rapid publication on acceptance

- support for research data, including large and complex data types

- gold Open Access which fosters wider collaboration and increased citations

- maximum visibility for your research: over $100 \mathrm{M}$ website views per year

At BMC, research is always in progress.

Learn more biomedcentral.com/submissions 